\title{
Voltage Quality Improvement of Microgrids under Islanding Mode
}

\begin{abstract}
Gustavo Azevedo ${ }^{1}$
Student Member

Marcelo Cavalcanti ${ }^{1}$

Member

Abstract -- This paper proposes a control strategy to reduce the voltage unbalance in microgrids. The voltage unbalance compensation is achieved by injection of a proper negativesequence current into the microgrid. This task can be done by each inverter connected to the microgrid. The current compensation reference is obtained through a negative-sequence voltage control loop, avoiding the load current measurement. This strategy does not require any hardware modification. This new control strategy is simulated in Matlab/Simulink to prove its effectiveness. Experimental results are also provide.
\end{abstract}

$\underset{\text { Member }}{\text { Pedro Rodriguez }^{2}}$

\author{
Joan Rocabert ${ }^{2}$ \\ Student Member
}

$\underset{\text { Member }}{\text { Francisco Neves }^{1}}$

\author{
${ }^{1}$ Federal University of Pernambuco - Department of Electrical Engineering, Recife - PE, Brazil \\ 2 Technical University of Catalonia - Department of Electrical Engineering - Terrassa, Spain \\ gustavomsa@aim.com, prodriguez@ee.upc.edu, rocabert@ee.upc.edu,marcelo.cavalcanti@ufpe.br, fneves@ufpe.br
}

Index Terms--Microgrids, distributed generation systems, unbalanced load.

\section{INTRODUCTION}

Power quality is a key issue in microgrids and a common problem is the voltage imbalance. Several works have been published on this topic. Three-phase low-voltage microgrids feed a large variety of loads. Some of these loads are singlephase, thus the currents delivered by the feeders, distributed along the microgrid, are unbalanced. Therefore the voltages across the line impedances and consequently the load voltages become unbalanced. Unbalanced voltages can cause abnormal operation particularly for sensitive loads and increase losses in motor loads. Each Distributed Generation (DG) unit in the microgrid is able to impose balanced voltage near itself. The inverter control strategy defines if its output voltage will be balanced or unbalanced. The inverters equipped with droop control [1], [2] can achieve balanced voltages because this strategy controls the inverter output voltage and frequency. However some DG sources, like photovoltaic and wind power, could not use droop control because their goal is to deliver all available power. These DG units are current controlled or power controlled, i.e., there is not output voltage control.

This paper proposes a control strategy to compensate negative-sequence voltage in the output of the inverters equipped with current control or power control. Consequently, it enhances the voltage quality around these inverters. The compensation can be achieved both in gridconnected or islanding mode, but the voltage unbalance level is higher under islanding mode due the reduction on shortcircuit power caused by the absence of the main source. The strategy is based on injection of negative-sequence current to supply, locally, the demanded of this current component. A simple way to do it is by measuring the load current, extracting its negative-sequence and injecting it through an inverter, like in [3]. However, in this paper a negativesequence control loop, based only on the microgrid voltage measurement, is used to determine the negative-sequence compensation reference. Thus, load current measurement is not necessary.

In the following, a brief explanation of the problem and a mathematical model that describes the phenomenon of the voltage imbalance due the unbalanced loads will be presented in section II. The proposed control algorithm will be presented in subsection IIa. Finally the performance of the proposed compensation method is evaluated by both simulations and experiments.

\section{NEGATIVE-SEQUENCE VOLTAGE COMPENSATION}

Figure 1(a) shows the Thévenin equivalent circuit of a microgrid, where $Z_{S}$ is the line impedance and $Z_{L}$ is the load impedance. If $Z_{L}$ is balanced the load current has only positive-sequence and the voltage across the line impedance has only positive-sequence too. On the other hand, if the load is unbalanced the load current has both positive- and negative-sequence. The latter component results on unbalanced voltage across the line impedance, and consequently across the load. The load voltage unbalance can be eliminated compensating the negative-sequence current demanded by the loads. An inverter connected near to the loads can be used to do it (as suggested in Fig 1(b)). Thus it is necessary a proper detection of the load current components to perform the compensation. Current sensors could be used, but they difficult the installation and increase 
the cost of the overall system. Besides, additional sensor can be necessary if there are loads on the upstream and downstream of the converter connection point.

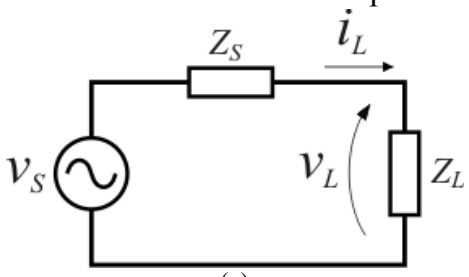

(a)

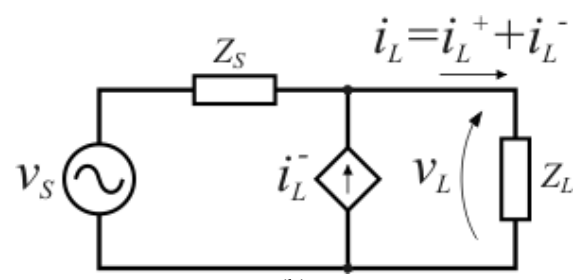

(b)

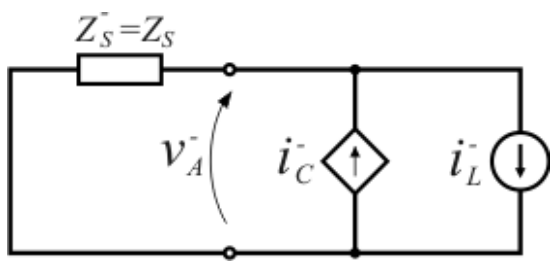

(c)

Fig. 1. Equivalent circuit of the microgrid. (a) without compensation, (b) with compensation (c) negative-sequence circuit

\section{A. Proposed Control}

The proposed compensation control estimates the current compensation using the grid negative-sequence voltage. The idea is to inject into the microgrid a current proportional to the negative-sequence voltage component measured on the inverter connection point.

Assuming that the voltage source of the system in Fig. 1(a) is balanced, the negative-sequence circuit that represents this system is shown in Fig. 1(c). The load was replaced by a current source that demands the same negative-sequence current of the load. When there is no compensation $\left(\mathbf{I}_{C}=0\right)$ the negative-sequence voltage at the load is given by:

$$
\mathbf{V}_{A}^{-}=-\mathbf{Z}_{S}^{-} \mathbf{I}_{L}^{-}
$$

where the superscript "_" denotes negative-sequence component. Equation (1) can be rewritten as

$$
\mathbf{I}_{L}^{-}=-\frac{\mathbf{V}_{A}^{-}}{\mathbf{Z}_{S}^{-}}
$$

Thus the compensation current injected by the converter should be

$$
\mathbf{I}_{C}^{-}=\mathbf{I}_{L}^{-}=-\frac{\mathbf{V}_{A}^{-}}{\mathbf{Z}_{S}^{-}}
$$

or

$$
\mathbf{I}_{C}^{-}=-Y \angle-\theta \mathbf{V}_{A}^{-}
$$

where $Y$ is the absolute value of the line admittance and $\theta$ is the line impedance phase angle. From (4) note that the compensation current is proportional to the negativesequence voltage and its phase angle is shifted $\pi-\theta$. The proposed compensation control is based on this fact for estimating the current compensation using only the negativesequence grid voltage measurement. The control algorithm calculates the absolute value of $\boldsymbol{V}$ and forces it to zero through a Proportional-Integral (PI) compensator. The control diagram is shown in Fig. 2. The first block is a sequence calculator based on a Dual Second Order Generalized Integrator DSOGI for quadrature-signal generator [4]. This block obtains the instantaneous negativesequence component of the converter output voltage vector on stationary reference frame. The magnitude of $\boldsymbol{V}$ passes through a Low-Pass Filter (LPF) to smooth the load transients and the voltage disturbances due to the injection of currents by the inverter. Finally, the last block of the negative-sequence compensator is a phase-shift operator to make the current compensation phasor in phase opposition to the negative-sequence load current. The phase-shift angle, $\theta$, is obtained by knowing the $\mathrm{X} / \mathrm{R}$ line ratio at the connection point of the inverter.

The primary power control can be made by the strategy presented in [5]. This strategy assures that the primary active power is delivered to the microgrid with balanced currents even if the voltages are unbalanced. The inverter reference current is the sum of these two controllers.

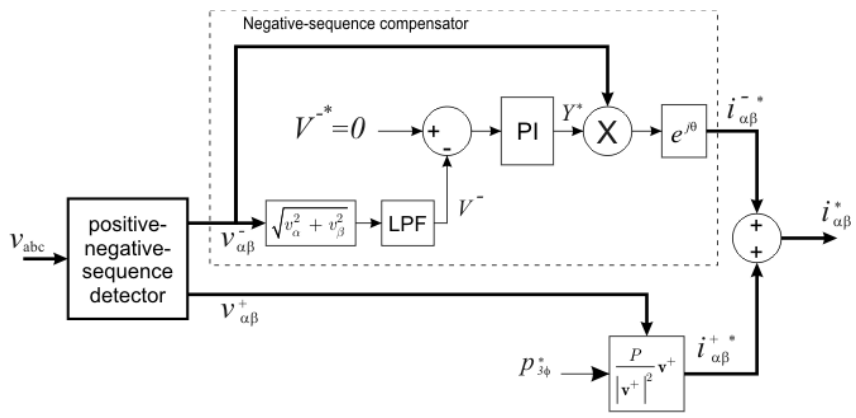

Fig. 2. Control diagram of the negative-sequence compensator

\section{Simulation RESUlTS}

The performance of the proposed control has been tested in simulations carried out in Matlab/Simulink, where a microgrid was modeled by one three-phase voltage source, the line equivalent impedance and some loads (one threephase and two single-phase). The single-phase loads are connected on phase $b$ through switches. The power converter is composed by a voltage source inverter and a LCL output 
filter. In order to simplify the simulation the primary source is considered a constant voltage source. The whole system is shown in Fig. 3. The system parameters are shown in Table I.

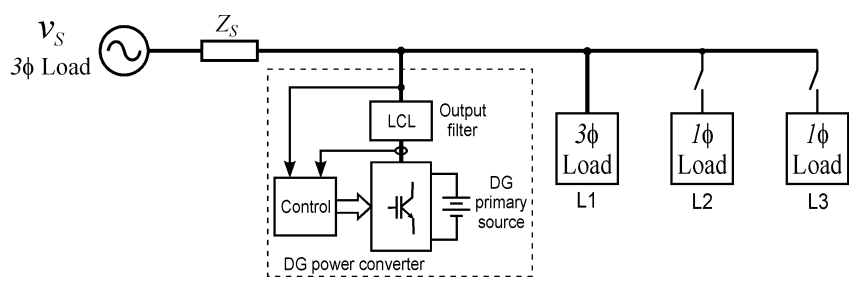

Fig. 3. Simulation set-up

TABLE I

SYSTEM PARAMETERS USED IN SIMULATION

\begin{tabular}{cc}
\hline Parameter & Value \\
\hline Load voltage (phase-to-phase) & $380 \mathrm{~V}$ \\
Equivalent line impedance, $\mathrm{Z}_{\mathrm{S}}$ & $0.8+\mathrm{j} 0.4 \Omega$ \\
Three-phase load power, $\mathrm{L}_{1}$ & $2000+\mathrm{j} 300 \mathrm{VA}$ \\
Single-phase load power, $\mathrm{L}_{2}$ & $1500+\mathrm{j} 50 \mathrm{VA}$ \\
Single-phase load power, $\mathrm{L}_{3}$ & $50+\mathrm{j} 1500 \mathrm{VA}$
\end{tabular}

In order to analyze the behavior of the proposed strategy for different load conditions, the simulation has three stages. In the first one ( 0 to $100 \mathrm{~ms}$ ), only the balanced load, $\mathrm{L}_{1}$, is connected to the microgrid. After that, $\mathrm{L}_{2}$ is connected too. At $400 \mathrm{~ms}$ the load $\mathrm{L}_{2}$ is disconnected and $\mathrm{L}_{3}$ is connected. Load $\mathrm{L}_{2}$ is basically resistive, whereas $\mathrm{L}_{3}$ is basically inductive. The microgrid voltage components are shown in Fig 4. In this case the compensation control was disabled. Note that the negative-sequence stays around $10 \mathrm{~V}$ when the unbalanced loads are connected.
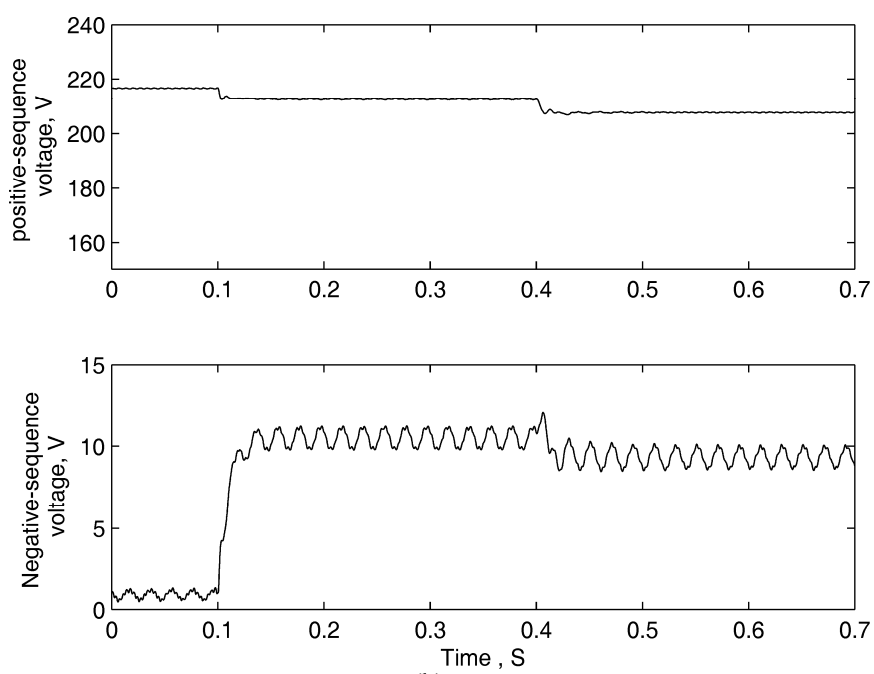

(b)

Fig. 4. Positive- and negative-sequence voltages components on the point of connection of the converter
The previous simulation is repeated with the compensation control enabled. The results are shown in Fig 5. The microgrid negative-sequence voltage is reduced to less than $2.5 \mathrm{~V}$, as shown in Fig 5(a). The current components consumed by the loads and delivered by the converter are shown in Fig 5(b). The converter positive-sequence current is approximately zero because it was considered that there is low primary power available to deliver to the microgrid. The converter negative-sequence current cannot reach the load current, but it is kept near to it. It occurs because for low levels of unbalance the sequence detector accuracy is not enough and consequently the negative-sequence compensation current references are wrong.
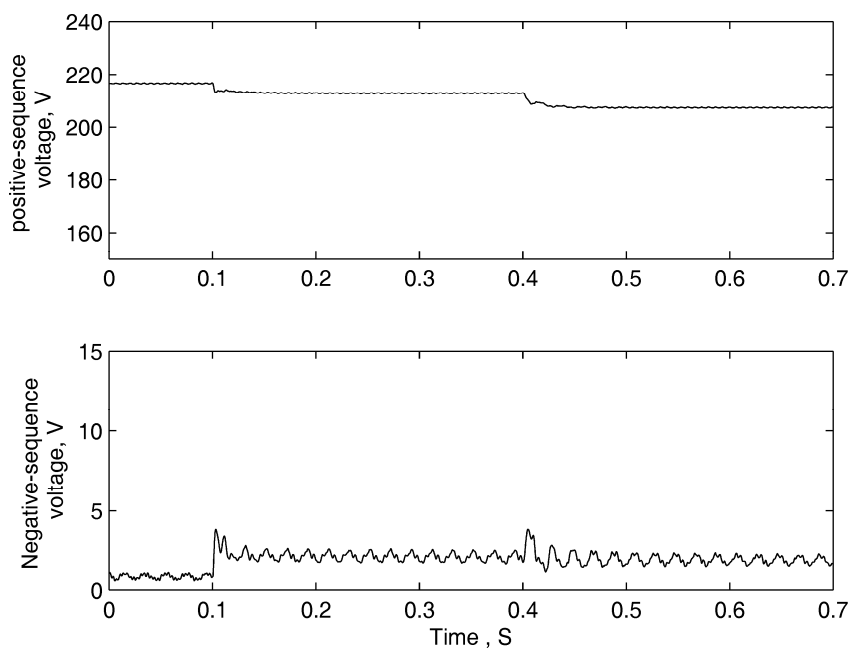

(a)
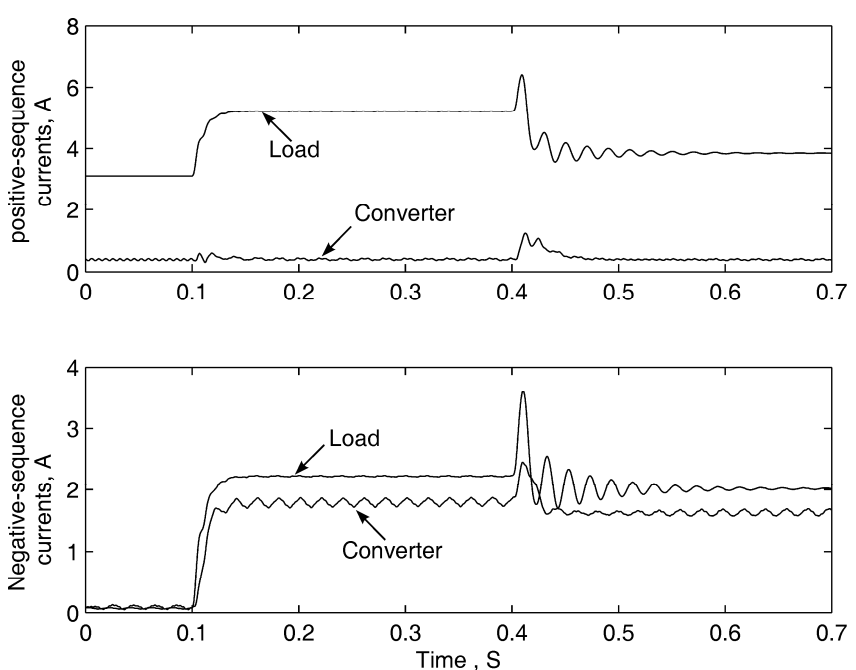

(b)

Fig. 5. Compensation results when the DG system was delivering low power. (a) positive- and negative-sequence voltages, (b) positive- and negative-sequence currents consumed by the loads and delivered by the converter 
When the primary power is available, it is delivered to the microgrid by positive-sequence currents. Figure 6 shows the simulation results when the inverter is delivering $1.5 \mathrm{~kW}$ and the loads are the same that were used before. Note that the negative-sequence compensation is not affected by the fact that the converter is delivering positive-sequence current.
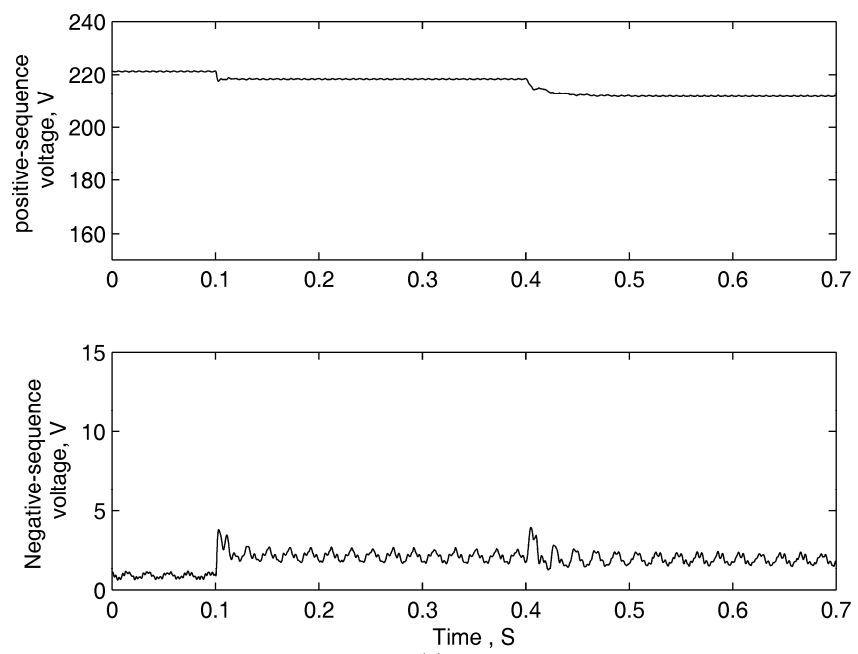

(a)
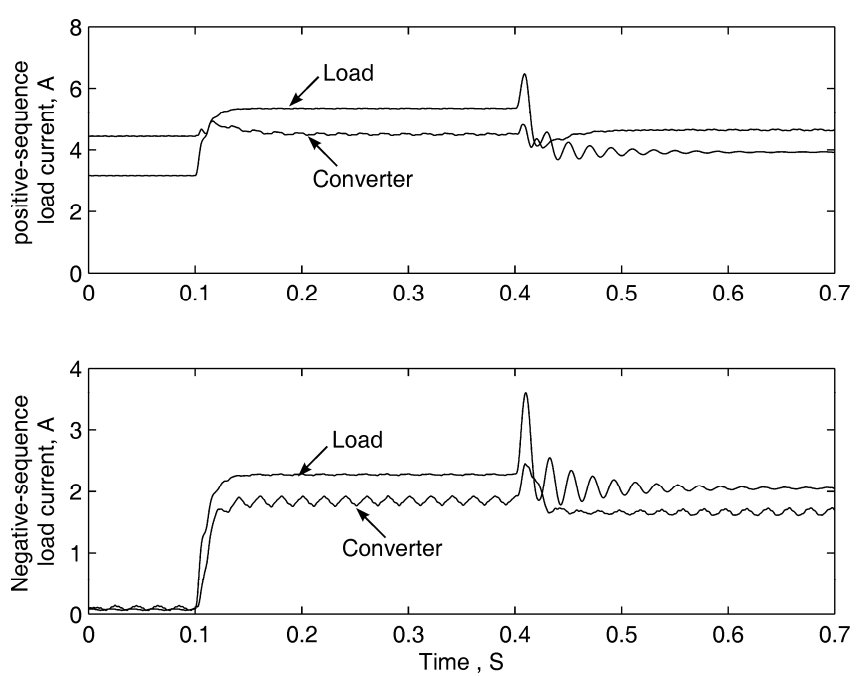

(b)

Fig. 6. Compensation results when the DG system was delivering $1.5 \mathrm{~kW}$. (a) positive- and negative-sequence voltages, (b) positive- and negativesequence currents consumed by the loads and delivered by the converter

\section{EXPERIMENTAL RESULTS}

The proposed voltage imbalance compensation was evaluated in an experimental set-up in which the microgrid (Fig. 7) was emulated by mean of the utility grid (emulating the microgrid equivalent voltage source) and a set of transformers (emulating the microgrid line impedance). The system voltage at point $A$ is $125 \mathrm{~V}_{\text {pico }}\left(88.4 \mathrm{~V}_{\mathrm{RMS}}\right.$ phase-toneutral) $/ 60 \mathrm{~Hz}$ and the equivalent resistance and reactance in this same point, due the transformers, is $1.7 \Omega$ and $6.4 \Omega$, respectively. The load bank has a balanced three-phase resistive load $\left(\mathrm{R}_{\mathrm{L} 2}=35.5 \Omega\right.$ per phase $)$ connected directly to the microgrid and a single-phase resistive load $\left(\mathrm{R}_{\mathrm{L} 1}=30.6\right.$ $\Omega)$, which can be switched to the phase b. The inverter dc side is fed by a dc power source with $350 \mathrm{~V}$. The inverter output is connected to the microgrid through a LCL filter. The control algorithm was implemented in a TMS320F2812, which is a fixed-point DSP of Texas Instruments that works at $150 \mathrm{MHz}$. The control sample time is $50 \mu \mathrm{s}$. The LPF cutoff frequency is set to $5 \mathrm{~Hz}$ and the phase-shift angle is set to 75 degrees. The current control is made on stationary reference frame using proportional-resonant controllers, as used in [5]. These controllers assure zero error on steadystate for sinusoidal signals.

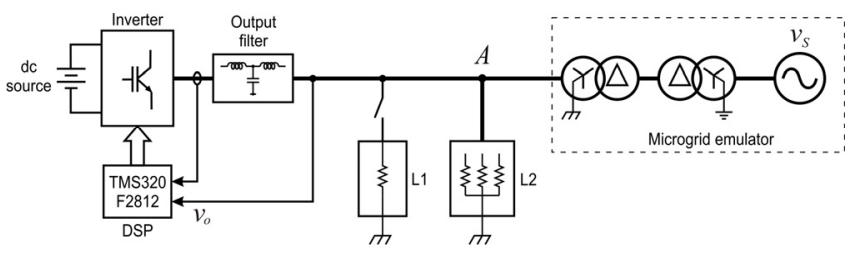

Fig. 7. Experimental set-up

The system voltages (point $A$ in Fig. 7) when the singlephase load is switched on are depicted in Fig. 8. Although the initially load is balanced, the voltages are a little bit unbalanced before switching on the single-phase load. This happened due the utility grid voltage imbalances. When the single-phase load is switched on the voltages become completely unbalanced. The negative-sequence component at this time is around $16 \mathrm{~V}$.

The negative-sequence voltage compensation behavior is shown in Fig. 9. The previous procedure is repeated with the compensation algorithm enabled. As it can be noticed comparing the Fig. 8 with Fig. 9, the voltage imbalance is lower when the compensation method is used. Moreover, it was also observed that the algorithm quickly starts to compensate the voltage and it stabilizes in about two cycles of the fundamental frequency.

In other experiment, the compensation algorithm begins deactivated and after some time the single-phase load is switched on, resulting unbalanced voltages. The compensation algorithm is enabled $150 \mathrm{~ms}$ later and the voltage imbalance is reduced. The negative-sequence voltage component, extracted from measured voltages, is shown in Fig. 10. As it can be noticed in this figure, the voltage imbalance rises to over than $15 \mathrm{~V}$ when the loads become unbalanced and it returns to approximately $2.5 \mathrm{~V}$ when the compensator is enabled. 


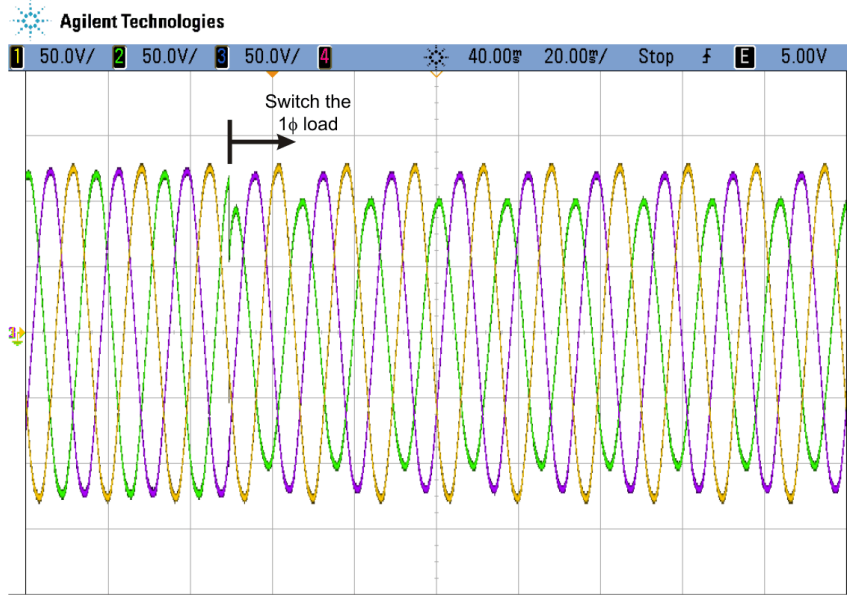

Fig. 8. Microgrid voltage when the single-phase load is switched on and the compensation algorithm is disabled

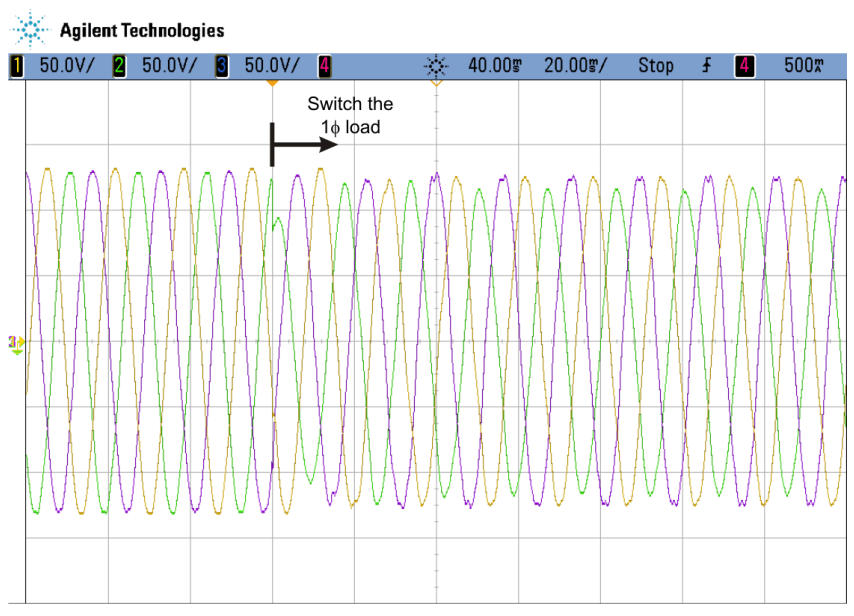

Fig. 9. Microgrid voltage when the single-phase load is switched on and the compensation algorithm is enabled

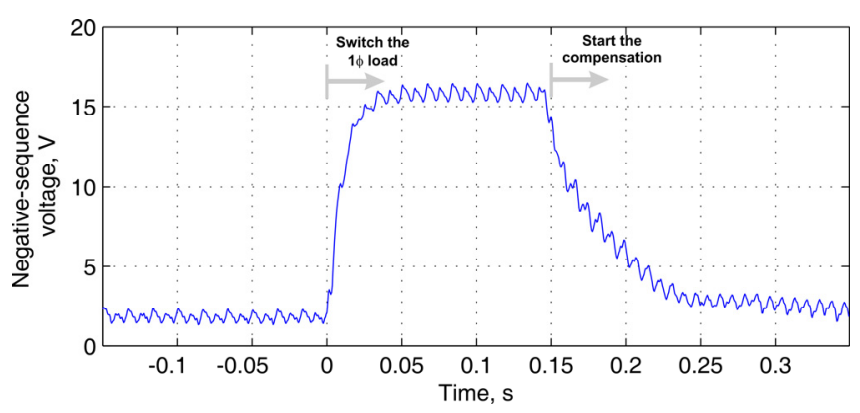

Fig. 10. Microgrid negative-sequence voltage component with and without the compensation algorithm

\section{CONCLUSIONS}

This paper proposes a control strategy to mitigate the unbalanced voltages in low-voltage three-phase microgrids. This control technique can be implemented in the DER converters without any modification on the hardware structure. It is not necessary any additional measurement sensor. The negative-sequence voltage compensation is not complete, but the simulation and experimental results show that the negative-sequence component stay below $2.5 \mathrm{~V}$. In the experimental results, the attenuation was around $85 \%$. Therefore it is a very good solution since it does not present any additional cost to the regular system.

\section{ACKNOWLEDGMENT}

This work was supported by the projects ENE200806841-C02-01/ALT and ENE2008-06588-C04-03/ALT financed by the Ministerio de Ciencia e Innovacion of Spain and also supported by the Coordenação de Aperfeiçoamento de Pessoal de Nível Superior (CAPES) - Brazil.

\section{REFERENCES}

[1] J.M. Guerrero, N. Berbel, J. Matas, J.L. Sosa, L.G. de Vicuna, "Droop Control Method with Virtual Output Impedance for Parallel Operation of Uninterruptible Power Supply Systems in a Microgrid," in Proc. IEEE APEC, Feb./Mar. 2007, pp. 1126-1132.

[2] L. Chia-Tse, C. Cheng-Chieh, C. Chia-Chi, C. Po-Tai, "Control strategies for distributed energy resources interface converters in the low voltage Microgrid," in Proc. IEEE ECCE, Sep. 2009, pp. 20222029.

[3] M. Hojo, Y. Iwase, T. Funabashi, Y. Ueda, "A method of three-phase balancing in microgrid by photovoltaic generation systems," in Proc. EPE-PEMC, Sep. 2008, pp. 2487-2491.

[4] P. Rodriguez, R. Teodorescu, I. Candela, A.V. Timbus, M. Liserre, F. Blaabjerg, "New Positive-sequence Voltage Detector for Grid Synchronization of Power Converters under Faulty Grid Conditions," in Proc. IEEE PESC, Jun. 2006, pp. 1-7.

[5] G.M.S. Azevedo, P. Rodriguez, M.C. Cavalcanti, G: Vazquez, F. Neves, "New control strategy to allow the photovoltaic systems operation under grid faults," Power Electronics Conference, 2009. COBEP '09. Brazilian , vol., no., pp.196-201, Sept. 27 2009-Oct. 1 2009 